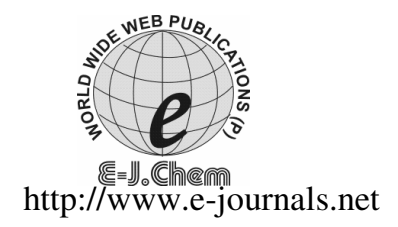

ISSN: 0973-4945; CODEN ECJHAO

E-Journal of Chemistry

2010, 7(1), 325-330

\title{
Corrosion Inhibition Effect of Dicycloimine Hydrochloride (DCI) on Mild Steel in $1 \mathrm{M} \mathrm{HCl}$
}

\author{
R. RAJALAKSHMI* and S. SUBHASHINI. \\ Avinashilingam University for Women, \\ Coimbatore - 641 043. Tamilnadu, India. \\ rajivardhan@gmail.com
}

Received 4 July 2009; Accepted 1 September May 2009

\begin{abstract}
Addition of corrosion inhibitors is one of the widely used methods to control corrosion. In the this work, an attempt has been made to explore the possibility of using dicycloimine hydrochloride (DCI) as an inhibitor on mild steel in $1 \mathrm{M} \mathrm{HCl}$. The inhibition efficiency of DCI has been evaluated by conventional weight loss method and electrochemical polarization studies. Experimental results are fitted to various adsorption isotherms. Thermodynamic parameters have also been studied from temperature studies. The results reveal that DCI acts as an effective inhibitor (around 90\% of IE) in $\mathrm{HCl}$ media.
\end{abstract}

Keywords: Corrosion, Inhibitors, DCI, Dicycloimine hydrochloride.

\section{Introduction}

Most large structures in industries are made by mild steel owing to its cheapness, availability and strength. In corrosive environments, mild steel is susceptible to corrosion attack and the losses incurred due to corrosion are estimated to be about 36,000 crores in India (NACE International India Section, Mumbai, 2007). $\mathrm{HCl}$ and $\mathrm{H}_{2} \mathrm{SO}_{4}$ are mainly employed for pickling, descaling, acidizing in mining and oil wells wherein mild steel suffers severe corrosion. Thus uninhibited acid solutions may be useless causing unnecessary dissolution of base metal.

Corrosion inhibitors are used in acid treatment solutions to significantly reduce the overall and local pickling attack and the hydrogen absorption of steel. It has been speculated that organic inhibitors are more effective with MS and specially polar organic compounds containing sulphur and nitrogen are good corrosion inhibitors for the acidic dissolution of metals ${ }^{1-7}$. The high electron density on the $\mathrm{S}$ and $\mathrm{N}$ atoms in these organic molecules help to get chemisorbed on the metal surface ${ }^{8}$. In the present work a study has been made on the effectiveness of dicycloimine hydrochloride (DCI) on corrosion of mild steel in $1 \mathrm{M} \mathrm{HCl}$ medium. 


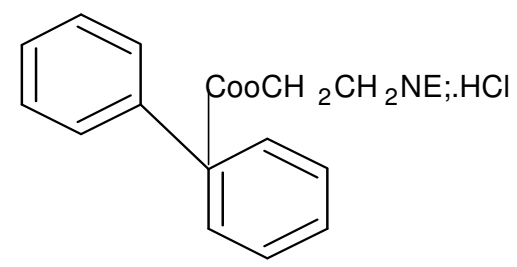

Scheme 1. Structure of 2-Diethyl aminoethyl-bicyclo hexy-1 carlcoxylate hydrochloride.

\section{Experimental}

The mild steel specimens were cut into $5 \mathrm{~cm} \times 1 \mathrm{~cm}$ coupons for immersion studies and were lacquered so as to expose an area of $1 \mathrm{~cm}^{2}$ for all electrochemical studies. The specimens were mechanically polished, degreased, dried in acetone and stored in a dessicator and used for all the studies. Their edges were abraded with fine grade of emery papers. Stock solutions of DCI were prepared and diluted to appropriate concentrations $\left(1 \times 10^{-2}\right.$ to $5 \times 10^{-6} \mathrm{M}$ ) with $1 \mathrm{M} \mathrm{HCl}$. Weight loss measurements were carried out in triplicate in the absence and presence of various concentrations of DCI at different time intervals at room temperatures and high temperatures. From the values, corrosion rate and inhibitor efficiency were determined.

Electrochemical studies were carried out using conventional three electrode cell with larger area platinum foil as counter electrode, MS as working electrode and saturated calomel electrode (SCE) as reference electrode. Solatron Electrochemical Analyser model (1280B) interfaced with an IBM computer and Zplot and Corrware softwares were used for data acquisition and analysis.

\section{Results and Discussions}

\section{Weight loss measurements: Effect of concentration}

Various corrosion parameters such as IE and corrosion rate obtained by weight loss method for different inhibitor concentrations at various time intervals in $1 \mathrm{M} \mathrm{HCl}$ are given in Table 1 . The percentage inhibition efficiency of the inhibitor increases with increase in inhibitor concentration. Maximum efficiency was achieved (Figure 1) at $10^{-2} \mathrm{M}$ concentration $(97.77 \%)$. This behaviour may be attributed to the increase of the surface area covered by the adsorbed molecules of DCI with the increase of concentrations ${ }^{6}$.

Table 1. Correlation between concentration of DCI, IE and time of immersion.

\begin{tabular}{|c|c|c|c|c|c|c|}
\hline \multirow{3}{*}{$\begin{array}{l}\text { Conc.of the } \\
\text { Inhibitor, } \mathrm{M}\end{array}$} & \multicolumn{6}{|c|}{ Immersion Time, $\mathrm{h}$} \\
\hline & 0.5 & 1 & 3 & 6 & 12 & 24 \\
\hline & \multicolumn{6}{|c|}{ Inhibition Efficiency, \% } \\
\hline Blank & - & - & - & - & - & - \\
\hline $5 \times 10^{-6}$ & 13.74 & 15.61 & 19.73 & 27.29 & 36.13 & 43.45 \\
\hline $10^{-5}$ & 17.49 & 24.15 & 30.19 & 39.07 & 47.32 & 52.19 \\
\hline $5 \times 10^{-5}$ & 27.40 & 33.70 & 38.91 & 45.47 & 51.26 & 56.89 \\
\hline $10^{-4}$ & 37.50 & 45.25 & 61.49 & 66.37 & 73.37 & 82.43 \\
\hline $5 \times 10^{-4}$ & 52.50 & 68.54 & 79.01 & 81.72 & 89.21 & 90.01 \\
\hline $10^{-3}$ & 60.00 & 72.76 & 80.90 & 87.62 & 91.13 & 92.36 \\
\hline $5 \times 10^{-3}$ & 78.75 & 82.69 & 86.64 & 93.35 & 94.86 & 95.21 \\
\hline $10^{-2}$ & 80.00 & 84.34 & 87.17 & 94.37 & 96.06 & 97.77 \\
\hline
\end{tabular}




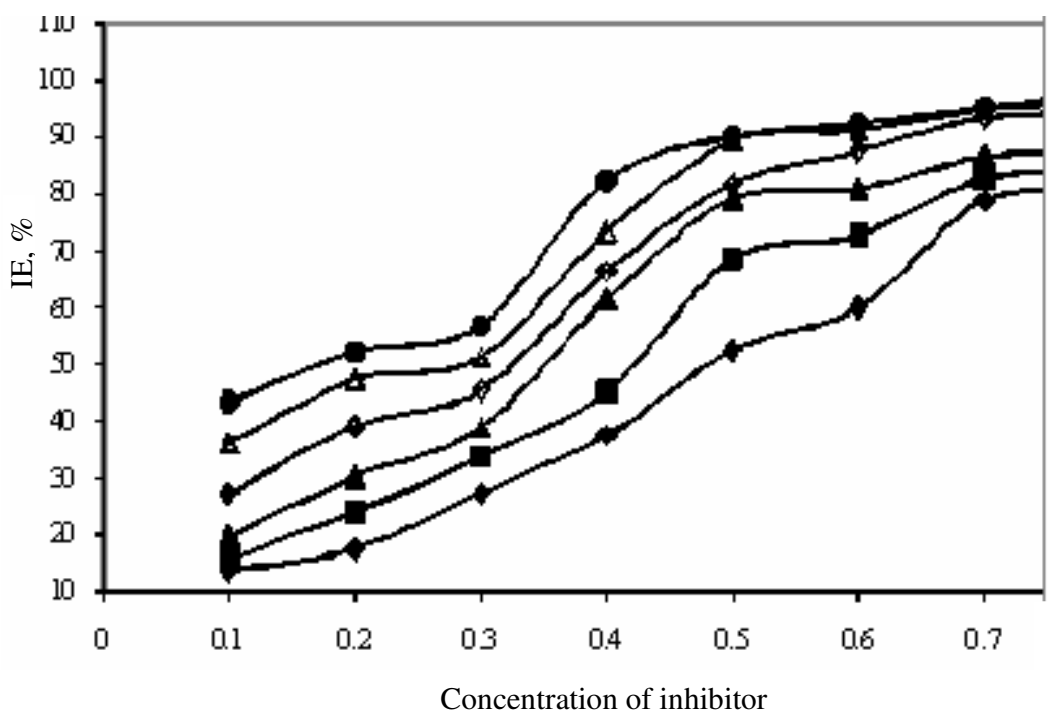

Figure 1. Effect of concentration inhibitor.

\section{Effect of immersion time}

From the table, it can be inferred that as the time of immersion increases, the IE increases. A maximum efficiency of $97.77 \%\left(10^{-2} \mathrm{M}\right.$ concentration) was obtained at $24 \mathrm{~h}$. This increase of IE with respect to time of immersion indicates the stability and persistence of the inhibitors films on the metal surface.

\section{Temperature effect}

To test the stability of the inhibitor at higher temperatures, experiments were performed at different temperatures in the range of $313 \mathrm{~K}-343 \mathrm{~K}$ (Table 2). As the temperature increased the IE was found to increase. At a critical concentration of inhibitor $\left(10^{-2} \mathrm{M}\right)$ a high protection efficiency was maintained over the temperature range of $313 \mathrm{~K}(81.3 \%)$ to $343 \mathrm{~K}$ $(86.48 \%)$. The enhancement in IE at high temperatures may be due to (i) higher activation energy is available for adsorption at higher temperatures (ii) enhancement in the surface coverage at high temperature by the inhibitor molecule ${ }^{9}$.

Table 2. IE as a function of concentration of DCI and temperature.

\begin{tabular}{cccccc}
\hline & \multirow{5}{*}{$\begin{array}{c}\text { Conc.of the } \\
\text { Snhibitor, No }\end{array}$} & \multicolumn{5}{c}{ Temperature, K } \\
\cline { 3 - 6 } & & \multicolumn{4}{c}{ Inhibition Efficiency, \% } \\
\hline 1 & Blank & & & & \\
2 & $5 \times 10^{-6}$ & 17.66 & 20.48 & 22.53 & 28.81 \\
3 & $10^{-5}$ & 19.49 & 29.70 & 33.46 & 38.8 \\
4 & $5 \times 10^{-5}$ & 31.05 & 41.30 & 44.64 & 47.58 \\
5 & $10^{-4}$ & 42.55 & 49.27 & 53.20 & 55.74 \\
6 & $5 \times 10^{-4}$ & 56.96 & 54.10 & 67.78 & 71.03 \\
7 & $10^{-3}$ & 60.57 & 63.76 & 69.56 & 76.04 \\
8 & $5 \times 10^{-3}$ & 79.41 & 80.67 & 81.39 & 81.92 \\
9 & $10^{-2}$ & 81.30 & 83.09 & 85.21 & 86.48 \\
\hline
\end{tabular}




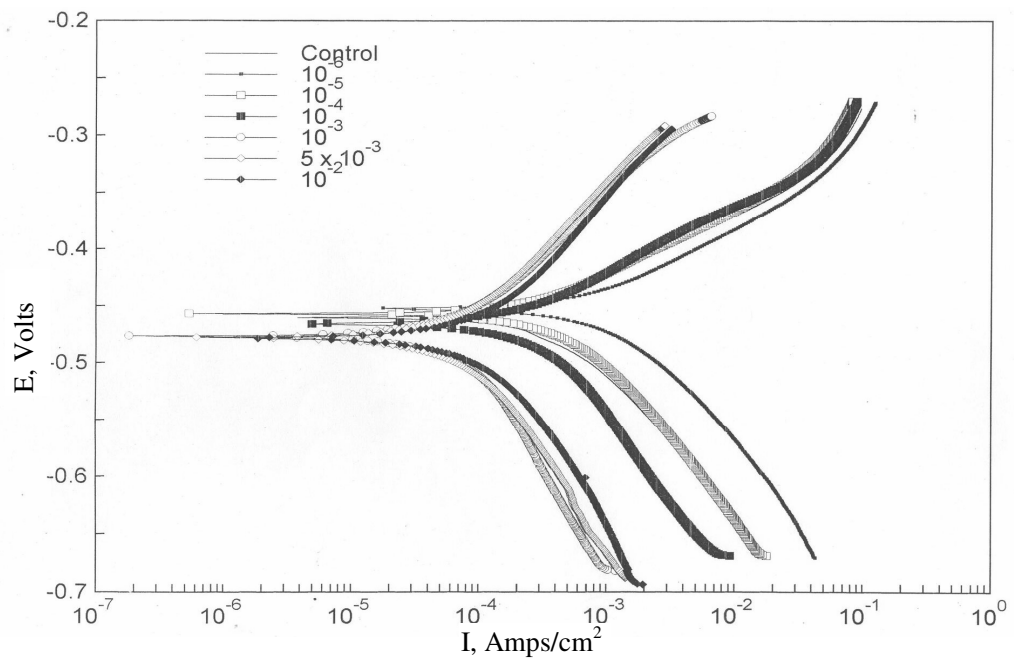

Figure 2. Polarization curves for mild steel in $1 \mathrm{M} \mathrm{HCl}$ with DCI.

\section{Kinetic and thermodynamic parameters}

An adsorption isotherm gives the relationship between the coverage of an interface with an adsorbed species (the amount adsorbed) and the concentration of the species in solution. From the suitable adsorption isotherm plot, the free energy of adsorption of the organic inhibitor is obtained ${ }^{10}$. Data were tested graphically by fitting various isotherms such as Langmuir and Temkin. From the linear plots of $\log \theta / 1-\theta v s \log C$ and $\theta v s \log C$ it can be seen that the inhibitor obeys both Langmuir and Temkin adsorption isotherms and this indicates that the main process of inhibition involves the adsorption of inhibitor on the metal surface. It may be attributed to the molecular interaction among the adsorbed particles and the metal surface and to the heterogeneity of the metal surface. Energy of activation values have been evaluated from Arrhenius equation.

$$
\log \mathrm{K}=-\mathrm{E}_{\mathrm{a}} / 2.303 \mathrm{RT}+\mathrm{C}
$$

( $\mathrm{K}$ is corrosion rate) and tabulated in Table 3. The decrease in $\mathrm{E}_{\mathrm{a}}$ value in the presence of inhibitor proves the chemical type of adsorption. Standard free energy values of adsorption $\left(\Delta \mathrm{G}_{\mathrm{ads}}\right)$ at different temperature were derived from Langmuir plots. The variation of $-\Delta \mathrm{G}$ with $\mathrm{T}$ are shown in Figure 3. From this $\Delta \mathrm{S}$ and $\Delta \mathrm{H}$ are calculated. The $\Delta \mathrm{G}$ values are negative and $\Delta \mathrm{H}$ is positive. Values of $\Delta \mathrm{S}$ are characteristics of strong interaction between the inhibitors and the metal surface forming a chemisorbed layer on the MS surface ${ }^{11}$.

Table 3. Kinetic and thermodynamic parameters.

\begin{tabular}{|c|c|c|c|c|c|c|c|c|}
\hline S. No & $\begin{array}{l}\text { Conc.of the } \\
\text { Inhibitor (M) }\end{array}$ & $\begin{array}{c}\text { Activation } \\
\text { Energy } \\
\mathrm{E}_{\mathrm{a}}=\mathrm{kJ} / \mathrm{mol}\end{array}$ & $\begin{array}{l}\text { Free } \\
313 \mathrm{~K} \\
\end{array}$ & $\begin{array}{l}\text { energy } \\
-\Delta \mathrm{G}=1 \\
323 \mathrm{~K}\end{array}$ & $\begin{array}{l}\text { of adso } \\
\text { kJ / mo } \\
333 \mathrm{~K}\end{array}$ & $\begin{array}{l}\text { rption } \\
343 \mathrm{~K}\end{array}$ & $\begin{array}{c}\text { Heat of } \\
\text { adsorption } \\
\Delta \mathrm{H}=\mathrm{kJ} / \mathrm{mol}\end{array}$ & $\begin{array}{c}\text { Entropy Change } \\
\Delta \mathrm{S}=\mathrm{J} \\
\operatorname{deg}^{-1} \mathrm{~mol}^{-1}\end{array}$ \\
\hline 1 & Blank & 50 & & & & & & \\
\hline 2 & $5 \times 10^{-6}$ & 46 & 38 & 39 & 41 & 43 & -18 & 0.1818 \\
\hline 3 & $10^{-5}$ & 43 & 36 & 39 & 41 & 42 & -25 & 0.1994 \\
\hline 4 & $5 \times 10^{-5}$ & 42 & 34 & 36 & 37 & 39 & -20 & 0.1740 \\
\hline 5 & $10^{-4}$ & 42 & 33 & 35 & 36 & 38 & -16 & 0.1601 \\
\hline 6 & $5 \times 10^{-4}$ & 39 & 30 & 31 & 34 & 35 & -17 & 0.1559 \\
\hline 7 & $10^{-3}$ & 39 & 29 & 30 & 32 & 34 & -16 & 0.1478 \\
\hline 8 & $5 \times 10^{-3}$ & 46 & 27 & 28 & 29 & 30 & -4 & 0.1036 \\
\hline 9 & $10^{-2}$ & 41 & 26 & 27 & 28 & 29 & -10 & 0.1183 \\
\hline
\end{tabular}




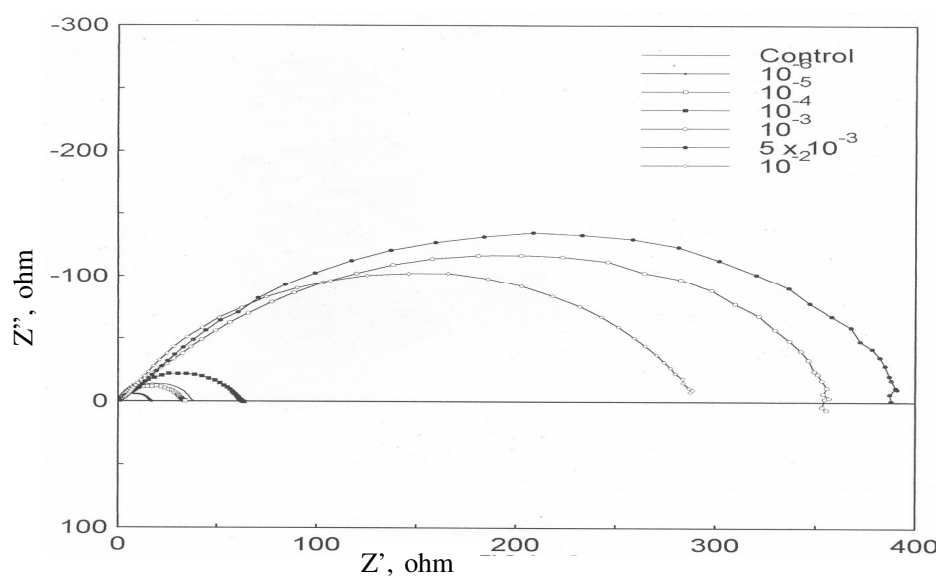

Figure 3. Nyquist plots for mild steel in $1 \mathrm{M} \mathrm{HCl}$ with DCI.

\section{Potentiodynamic polarization studies}

Both the anodic and cathodic polarization behaviour of mild steel in $1 \mathrm{M} \mathrm{HCl}$ in the absence and presence of DCI. Electrochemical parameters and inhibitor efficiency (IE\%) for different concentrations are given in Table 4.

Table 4. Polarization studies of $\mathrm{MS}$ in $\mathrm{HCl}$ in the presence of DCI.

\begin{tabular}{cccccc}
\hline $\begin{array}{c}\text { Conc.of the } \\
\text { Inhibitor, } \mathrm{M}\end{array}$ & $\mathrm{E}_{\text {corr }} \mathrm{mV} / \mathrm{sec}$ & $\mathrm{I}_{\text {corr }} \mathrm{mA} / \mathrm{dec}$ & $\mathrm{b}_{\mathrm{a}} \mathrm{mV} / \mathrm{dec}$ & $\mathrm{b}_{\mathrm{c}} \mathrm{mV} / \mathrm{dec}$ & $\mathrm{IE} \%$ \\
\hline Control & -473 & $1.7 \times 10^{-3}$ & 112 & 151 & \\
$10^{-5}$ & -491 & $4.08 \times 10^{-4}$ & 67 & 125 & 76 \\
$10^{-4}$ & -488 & $2.01 \times 10^{-4}$ & 65 & 153 & 88.17 \\
$10^{-3}$ & -494 & $0.71 \times 10^{-4}$ & 107 & 186 & 95.82 \\
$5 \times 10^{-3}$ & -498 & $0.66 \times 10^{-4}$ & 115 & 149 & 96.11 \\
$10^{-2}$ & -486 & $0.55 \times 10^{-4}$ & 120 & 157 & 96.76 \\
\hline
\end{tabular}

The $\mathrm{I}_{\text {corr }}$ values decrease considerably in the presence of different concentrations of inhibitor. The $\mathrm{E}_{\text {corr }}$ values are slightly shifted in the presence of inhibitors suggesting that these inhibitors inhibit the corrosion of mild steel in $\mathrm{HCl}$ by controlling both the anodic and cathodic reactions. Inhibitors of this type are known as mixed type inhibitors. The change in the values of $b_{a}$ and $b_{c}$ in the presence of DCI also infer that the inhibitor behaves as mixed type indicator.

\section{Electrochemical impedance spectroscopy}

The corrosion behaviour of mild steel in acid solution in the presence of DCI in $1 \mathrm{M} \mathrm{HCl}$ was investigated by EIS method at room temperature. Various impedance parameters such as charge transfer resistance $\left(\mathrm{R}_{\mathrm{ct}}\right)$, double layer capacitance $\left(\mathrm{C}_{\mathrm{dl}}\right)$ and inhibition efficiency (IE) are given in Table 5 .The impedance diagrams are found to be almost semi circle in appearance but not perfect semicircles. This difference has been attributed to the frequency dispersion. From the impedance parameters, it can be seen that as the DCI concentration increased $R_{c t}$ values were found to increase but $C_{d l}$ values decreases. The decrease in $C_{d l}$ values was caused by the adsorption of DCI molecule on the metal surface. Decrease in $\mathrm{C}_{\mathrm{dl}}$ which can result from a decrease in local dielectric constant and / or an increase in the thickness of the electrical double layer, suggests that the DCI functions by adsorption at the 
metal - solution interface ${ }^{12}$. The change in $R_{c t}$ and $C_{d l}$ values was caused by the gradual replacement of by adsorption of the organic molecules on the metal surface decreasing the extent of dissolution reaction ${ }^{13}$.Maximum IE was found to be $95 \%$ from electrochemical techniques.

Table 5. Electrochemical Impedance parameters of MS in the presence of DCI.

\begin{tabular}{ccccccc}
\hline $\begin{array}{c}\text { Conc.of the } \\
\text { Inhibitor, }(\mathrm{M})\end{array}$ & $\begin{array}{c}\mathrm{R}_{\mathrm{CT}} \\
\mathrm{Ohm} / \mathrm{cm}^{2}\end{array}$ & $\mathrm{IE} \%$ & $\begin{array}{c}\mathrm{Cdl} \\
\mu \mathrm{F} / \mathrm{cm}^{-2}\end{array}$ & $\theta$ & $\begin{array}{c}\mathrm{R}_{\mathrm{p}} \\
\mathrm{Ohm} / \mathrm{cm}^{2}\end{array}$ & $\mathrm{IE} \%$ \\
\hline Control & 14.3 & & 56.50 & & 16.16 & \\
$10^{-5}$ & 36.0 & 60.27 & 22.95 & .59 & 40 & 58.5 \\
$10^{-4}$ & 62.0 & 76.93 & 13.77 & .75 & 63 & 74.34 \\
$10^{-3}$ & 287.0 & 95.01 & 2.98 & .94 & 290 & 94.42 \\
$5 \times 10^{-3}$ & 363.0 & 96.06 & 2.34 & .95 & 371 & 95.64 \\
$10^{-2}$ & 391.0 & 96.34 & 2.19 & .96 & 396 & 95.91 \\
\hline
\end{tabular}

\section{Conclusion}

DCI is found to be a promising inhibitor for mild steel in $1 \mathrm{M} \mathrm{HCl}$. The IE increased with increase in concentration and, immersion time of the inhibitor. The inhibitor is found to be stable even at higher temperatures. It is found to obey Langmuir and Temkin adsorption isotherms. Kinetic and thermodynamic parameters revealed a strong interaction between MS surface and the inhibitor forming a chemisorbed layer. The polarization data indicated suppression of both the partial corrosion processes in the presence of DCI. Experimental studies revealed that DCI behaved as mixed type inhibitor. Results obtained by using weight loss method and electrochemical methods are quite comparable.

\section{References}

1. Hackerman N and Hurd R M, Corrosion, 1961, 116, 166.

2. Hackerman N, Symposium on Advances in Chelate Chemistry, Brookllyn Polytechnic Institute, 1955, 30.

3. Chatterjee P, Benerjee M K and Makherjee K P, Indian J Technol., 1991, 29, 191.

4. Elachouri M, Hajji M S, Kertit S, Essassi E M, Salem M and Courert R, Corr Sci., 1995, 37, 381.

5. Mernari B, Elattari H, Traisnel M and Bentsis F, Corr Sci., 1998, 40, 391.

6. Bentiss F, Traisnee M and Lagrenee M, Corr Sci., 2000, 42, 127.

7. ElkadiL, Mernari B, Traisnel M, Benliss F and Lagrenee M, Corr Sci., 2000, 42, 703.

8. Iita B and Offiong O E, Mater Chem Phys., 1999, 60, 79.

9. Chaturvedi and Chaudhary R H, Corrosion Prevention and Control, 1990, 5-13.

10. Cao chu nan and Zhou Sanggi, $10^{\text {th }}$ International Congress on metallic corrosion, 1987, 8, $2777-2785$.

11. Bag S K, Chakraborthy S B and Chaudri, J Indian Chem Soc., 1996, 73, 113- 118.

12. Cafferty E Mc and Hackerman N, J Electrochem Soc., 1972, 119, 146.

13. Muralidharan S, Phani K L N, Pitchamani S, Ravichandran S and Iyer S V K, J Electrochem Soc., 1995, 142, 1478. 


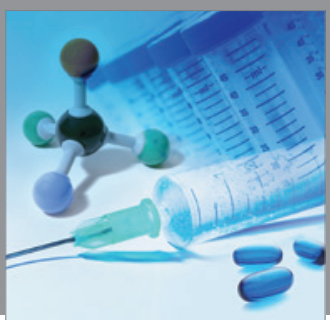

International Journal of

Medicinal Chemistry

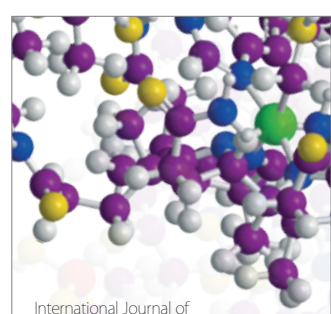

Carbohydrate Chemistry

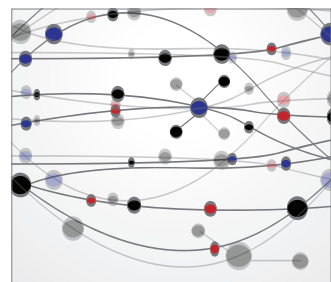

The Scientific World Journal
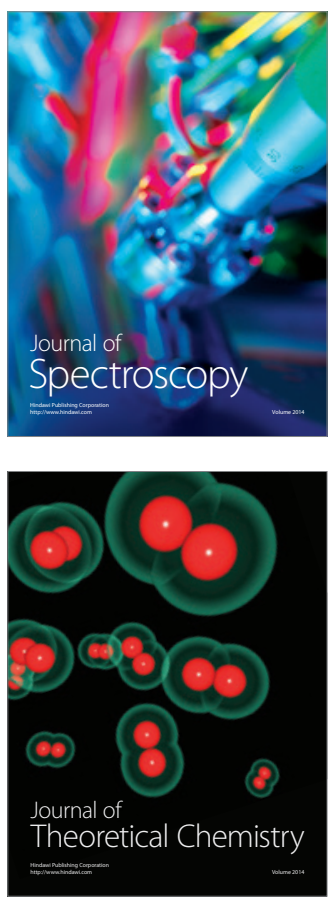
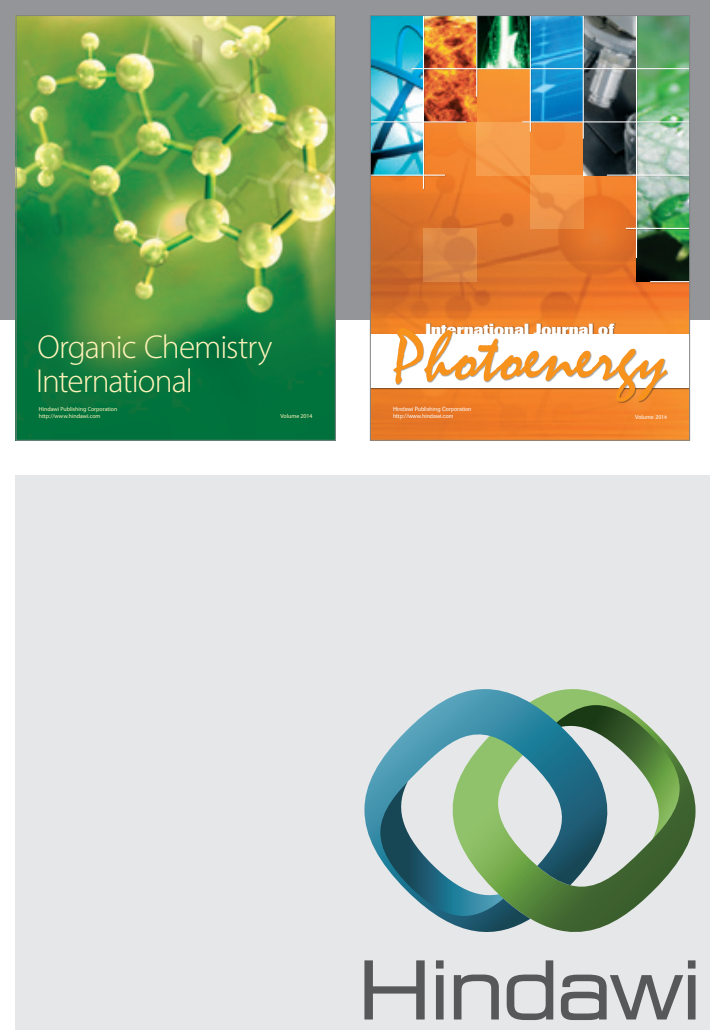

Submit your manuscripts at

http://www.hindawi.com
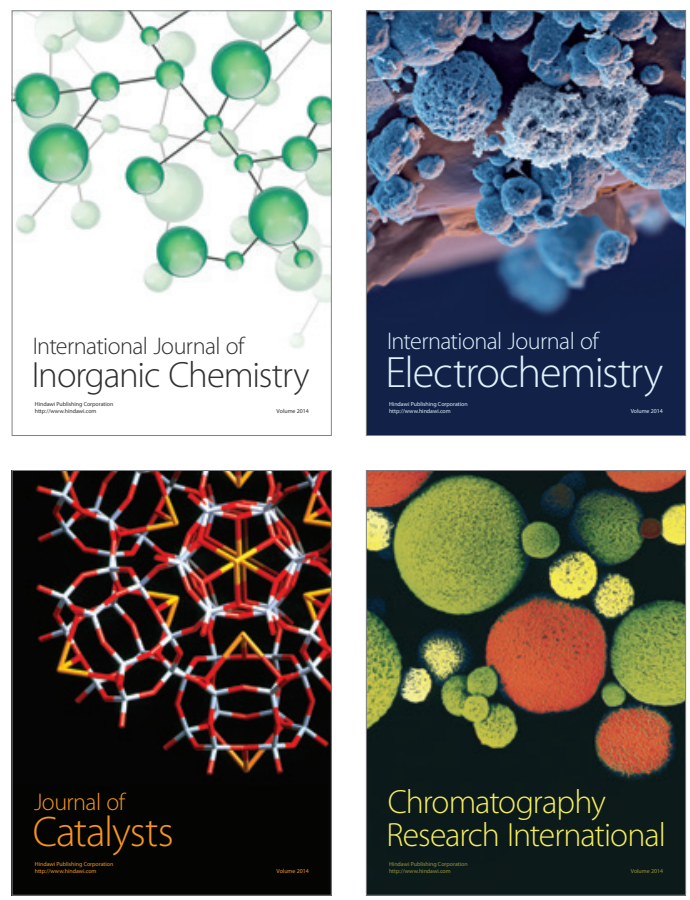
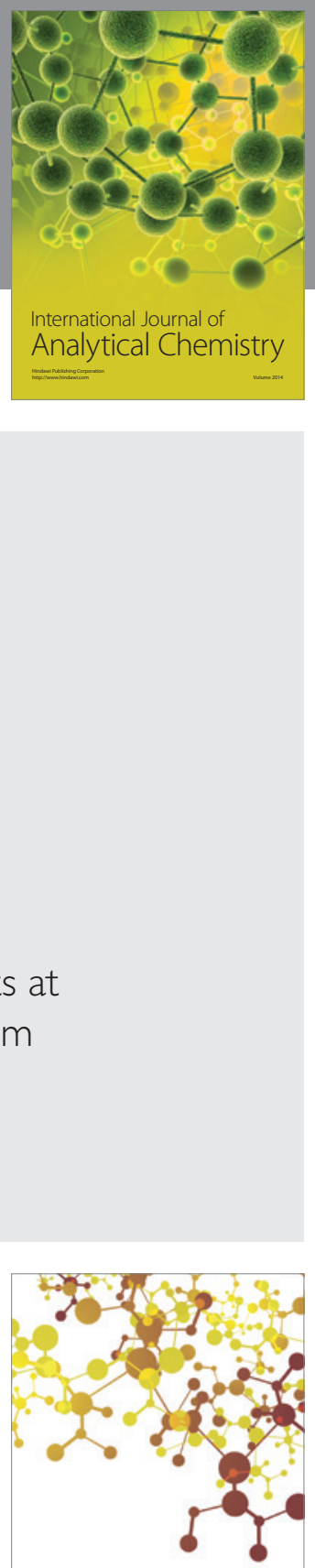

Journal of

Applied Chemistry
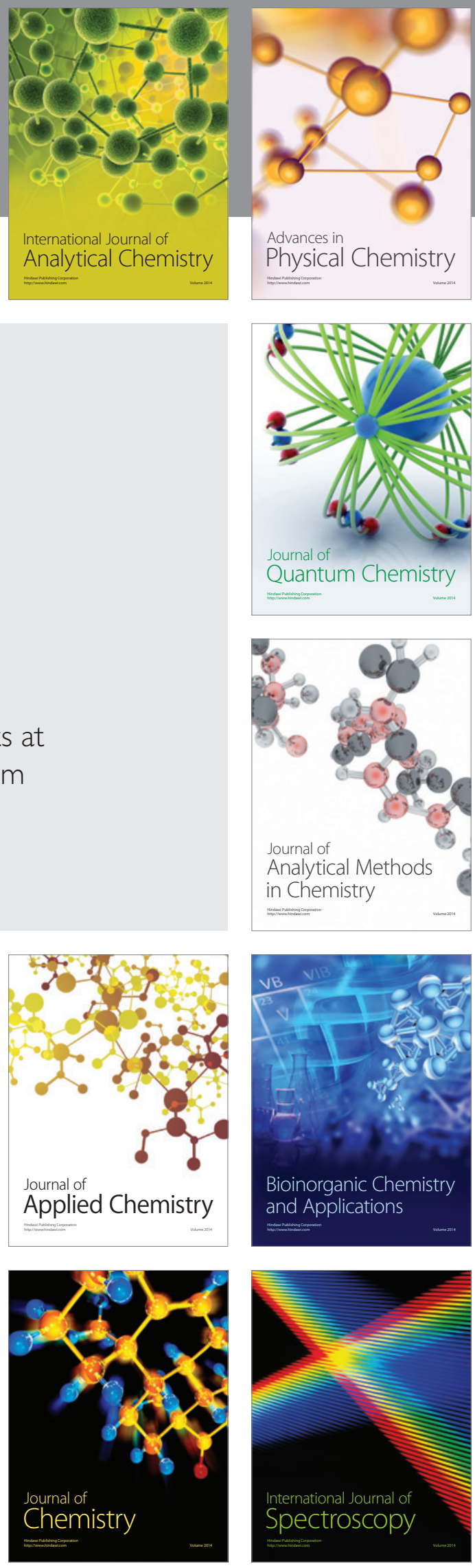